\title{
Cross-country connectedness in inflation and unemployment: measurement and macroeconomic consequences
}

\author{
Binh Thai Pham ${ }^{1}$ (D) Hector Sala ${ }^{2,3}$
}

Received: 29 May 2020 / Accepted: 26 March 2021 / Published online: 20 April 2021

(c) The Author(s), under exclusive licence to Springer-Verlag GmbH Germany, part of Springer Nature 2021

\begin{abstract}
We bring the notion of connectedness (Diebold and Yilmaz, Int J Forecast 28(1):5766 2012) to a set of two critical macroeconomic variables as inflation and unemployment. We focus on the G7 economies plus Spain, and use monthly data-highfrequency data in a macro setting-to explore the extent and consequences of total and directional volatility spillovers across variables and countries. We find that total connectedness is larger for prices (58.28\%) than for unemployment (41.81\%). We also identify asymmetries per country that result in higher short-run Phillips curve trade-offs in recessions and lower trade-offs in expansions. Besides, by exploring time-varying connectedness (resulting from country-specific shocks), we find that volatility spillovers magnify in periods of common economic turmoil such as the Global Financial Crisis. Our results call for an enhancement of international macroeconomic policy coordination.
\end{abstract}

Keywords Country-specific shocks $\cdot$ Connectedness $\cdot$ Philips curve $\cdot$ G7 $\cdot$ Common shocks

JEL classifications $\mathrm{C} 32 \cdot \mathrm{C} 50 \cdot \mathrm{E} 24 \cdot \mathrm{F} 41 \cdot \mathrm{F} 42$

Binh Thai Pham

binhpt@ueh.edu.vn

1 School of Public Finance, University of Economics Ho Chi Minh City, Ho Chi Minh City, Vietnam

2 Departament D’Economia Aplicada, Universitat Autònoma de Barcelona, Barcelona, Spain

3 Institute for the Study of Labor (IZA), Bonn, Germany 


\section{Introduction}

Cyclical synchronization across countries is considered the outcome of common shocks - for example, the financial crisis in 2008 and the Covid-19 crisis in 2020-, or the transmission of country-specific shocks. For common shocks, synchronization takes place through trade integration, financial integration, or even 'animal spirits' (De Grauwe and Ji, 2017). For country-specific shocks, transmission channels should not be different from those that operate in spreading the impact of common shocks. The intriguing issue, however, is to know the extent to which the impact of country-specific shocks reaches an economy's trade and financial partners. This is the object of the connectedness index developed by Diebold and Yilmaz (2009, 2014, and 2015; hereafter DY), which is agnostic on how connectedness arises, but most useful to understand the extended consequences of such shocks.

Connectedness has been investigated for asset returns (Diebold and Yilmaz 2009), financial institutions (DY, 2014), and the business cycle (Antonakakis et al., 2015; Diebold and Yilmaz 2015). Still, the macroeconomic evidence of connectedness is scarce in comparison with research that is more abundant in the financial literature. The first macroeconomic analysis is due to Diebold and Yilmaz (2015), who showed that the cross-country co-movement of business fluctuations varies substantially over time in the G7 countries. ${ }^{1}$ Along the same line, Antonakakis et al. (2015) uncovered the existence of remarkable spillover effects between credit growth and output growth in the G7 economies. Miescu (2019), instead, proposed a nonlinear VAR approach to estimate the DY indices for industrial production, inflation, and stock price growth rates. The author confirmed and extended DY's (2015) results, and showed that European countries appear to be highly sensitive to fundamental shocks from the USA and Japan. Meanwhile, the US economy was found relatively immune to its trading partners' innovations. Most notably, Antonakakis and Badinger (2016) found that the output spillover levels of G7 countries were unprecedentedly high during the Global Financial Crisis and that the US is the largest transmitter of output volatility.

This paper takes a step forward with respect to the extant literature. It considers asymmetries in connectedness across two key macroeconomic variables, the rates of inflation and unemployment, and infers its consequences for the critical trade-off between the two. This is known as the Phillips curve trade-off and plays a fundamental role not only in terms of forecasting but also in relation to the corresponding sacrifice ratio: the cost in terms of unemployment of bringing inflation down.

What are the implications, for inflation, unemployment, and the trade-off between the two, of asymmetries in the transmission of country-specific shocks? What can we learn from such implications in terms of the forecasting accuracy of the Phillips curve trade-off? Is it possible to identify different consequences in expansionary and recessive periods? Is time-varying connectedness revealing of specific patterns through time? Is the identification of such patterns useful for the conduct of

\footnotetext{
1 Diebold and Yilmaz (2015) actually excluded Canada from the industrial production dataset due to the high correlation between Canada and the United States.
} 
economic policy? We aim to respond to these questions by exploiting the information obtained from the connectedness indices of the G7 economies (namely Canada, France, Germany, Italy, Japan, the United Kingdom, and the United States) and Spain. $^{2}$

Another novelty is the use of monthly data that, in terms of the standards of macroeconomic analysis, can be considered as high-frequency data. Although the use of such data is uncommon in the related literature, Miescu (2019) is an exception to which this paper adds. The use of monthly data on CPI inflation and the unemployment rate is advantageous for a twofold reason. First, it allows focusing on a recent period, January 1991-December 2019, with enough degrees of freedom for estimation. Second, it will enable a much reliable short-run analysis, since the volatility spillovers need to be examined within a close timeline after the shock hits the economy.

The methodology we use is the one presented in DY $(2012,2015)$, where the variable cointegration order is taken into account. This implies that we scrutinize the non-stationary characteristics of the unemployment rate and the consumer price index through a battery of linear and nonlinear unit root tests. To ensure robustness, we perform two different analyses. First, time-varying DY spillovers are thoroughly examined by rolling estimations. Second, we apply Caloia et al.'s (2019) alternative normalization schemes to gain further insights on both the strength of connectedness and its net directional effect.

Our findings are as follows. First total connectedness is larger for the nominal variable-prices (58.28\%) - than for the real variable-unemployment $(41.81 \%)$. As expected, these values are below those reported for financial connectedness (DY, $2009,2014)$. Irrespective of whether the level of connectedness is relatively high (as for prices) or low (as for unemployment), directional spread to others is much more diverse than directional spread from others. In addition, there seems to be an association between competitiveness (positive current account balances) and prominence of the directional spread from others over directional spread to others. This suggests that economies that are more competitive have the ability to cushion the impact of shocks largely than non-competitive economies, whose shocks spread out widely to others. In particular, we find the USA and Spain to be strong net transmitters of volatility.

Concerning unemployment, we find own connectedness to be high, confirming that unemployment volatility in response to shocks is essentially an internal matter. This result does not preclude the fact that connectedness is also high in some cases. We argue that such evidence opens the door to consider some supranational coordination in terms of labor market policies, even though such policies are generally regarded as a pure national matter. This is connected to another relevant policy issue such as the inflation-unemployment trade-off. We find evidence that connectedness

\footnotetext{
${ }^{2}$ We consider Spain on account of its idiosyncratic behavior regarding its Phillips curve responses (Ball et al. 2017; Pham and Sala, 2019). In the Online Appendix, we supply all the information when only the G7 countries are considered. The presence or absence of Spain in the sample neither affects the essence of the results nor the conclusions reached for the G7 countries.
} 
acts as an enhancer of short-run Phillips curve trade-offs during recessions but diminishes such trade-offs in expansions. This generates a twofold incentive for policy makers to increase cross-country coordination. First, to avoid spillovers from other country-specific shocks, and second to avoid larger sacrifice ratios when having to bring inflation down in periods of economic downturns.

A third important finding relates to our results on time-varying connectedness, which appears as an additional transmission channel for the effects of common shocks. This evidence arises from the jump in the spread of volatility spillovers resulting from country-specific shocks in periods of global economic turmoil such as the one around the GFC. Again, we believe that an extra degree of coordination in macroeconomic policies could be desirable to boost (real) economic convergence in view to diminish volatility spillovers caused by shocks. It is especially so in the case of unemployment shocks due to their far-reaching social implications. Beyond real convergence, which is more of a long-term issue (Monfort et al., 2018), coordination in the political response could help in reducing volatility spillovers more effectively in the aftermath of such shocks.

In what follows, Sect. 2 deals with preliminary empirical issues including a univariate time series analysis to ascertain the correct estimation method. Section 3 shows the results of the connectedness indices and their implications for the G7 countries and Spain. Sections 4 and 5 provide evidence on time-varying connectedness and robustness. Section 6 concludes.

\section{Empirical issues}

We use the latest version of DY's (2009, 2014, and 2015) directional connectedness index, which has been progressively refined and whose main features are summarized in the Online Appendix. One key methodological issue refers to the index's normalization method, which admits different possibilities. In order to assess the robustness of DY's (2012) row sum rule, we apply three alternative rules suggested in Caloia et al. (2019), namely max row normalization, max column normalization, and spectral radius normalization.

\subsection{Data}

We collect seasonally adjusted monthly data for the unemployment rate (UNRATE) and consumer price index (CPI) from the OECD Main Economic Indicators (MEI) database. To be consistent across G7 countries and Spain, the harmonized all-persons UNRATE (series LRHUTTTT) and the all-items CPI (series CPIALLMINMEI) were selected. Moreover, we intentionally focus on the sample period from 1991 through 2019 since the year 1991 marks the actual end of the Cold War, the beginning of a new stage in the European integration process and, more generally, a new globalization era.

Table 1 provides descriptive statistics of our variables. As it is well-known, there is an Anglo-Saxon model characterized by low unemployment rates, especially in 
Table 1 Descriptive statistics

\begin{tabular}{lllllllll}
\hline UNRATE & US & JP & DE & FR & GB & IT & CA & ES \\
\hline Mean & 5.849 & 3.811 & 7.229 & 9.898 & 6.430 & 9.673 & 7.792 & 16.584 \\
Median & 5.500 & 3.900 & 7.750 & 9.500 & 5.900 & 9.900 & 7.300 & 16.700 \\
Maximum & 10.000 & 5.500 & 11.200 & 12.500 & 10.400 & 13.100 & 12.100 & 26.300 \\
Minimum & 3.500 & 2.000 & 3.100 & 7.200 & 3.700 & 5.800 & 5.400 & 7.900 \\
Std. Dev & 1.623 & 0.991 & 2.192 & 1.415 & 1.796 & 1.775 & 1.579 & 5.146 \\
Skewness & 0.865 & -0.138 & -0.264 & 0.460 & 0.486 & -0.248 & 0.878 & 0.034 \\
Kurtosis & 2.928 & 1.886 & 1.999 & 2.151 & 2.102 & 1.992 & 2.889 & 1.919 \\
Jarque-Bera & 43.482 & 19.092 & 18.576 & 22.698 & 25.383 & 18.304 & 44.896 & 17.027 \\
Probability & 0.000 & 0.000 & 0.000 & 0.000 & 0.000 & 0.000 & 0.000 & 0.000 \\
DLCPI & US & JP & DE & FR & GB & IT & CA & ES \\
Mean & 0.188 & 0.029 & 0.146 & 0.124 & 0.185 & 0.188 & 0.154 & 0.213 \\
Median & 0.191 & 0.000 & 0.118 & 0.122 & 0.234 & 0.187 & 0.154 & 0.243 \\
Maximum & 1.215 & 2.031 & 1.730 & 1.007 & 2.065 & 0.874 & 2.594 & 1.573 \\
Minimum & -1.934 & -0.834 & -1.036 & -1.006 & -0.703 & -0.581 & -1.043 & -1.925 \\
Std. Dev & 0.323 & 0.336 & 0.347 & 0.282 & 0.321 & 0.214 & 0.359 & 0.504 \\
Skewness & -1.017 & 1.268 & 0.307 & -0.270 & 0.090 & -0.298 & 0.725 & -0.603 \\
Kurtosis & 8.860 & 9.399 & 5.020 & 3.915 & 6.376 & 3.795 & 8.968 & 4.863 \\
Jarque-Bera & 557.869 & 686.987 & 64.607 & 16.362 & 165.720 & 14.302 & 546.866 & 71.399 \\
Probability & 0.000 & 0.000 & 0.000 & 0.000 & 0.000 & 0.001 & 0.000 & 0.000 \\
Obs & 348 & 348 & 348 & 348 & 348 & 348 & 348 & 348 \\
\hline & & & & & & & 0.000 \\
\end{tabular}

the USA, where it oscillates around values below 6\%. In the European countries, this average is generally closer to $10 \%$, with the exception of Spain. Spain records the second to the highest value within the OECD countries and the largest volatility among the countries considered in contrast to Japan, which is characterized by a specific labor market relations system, and displays the lowest average unemployment rate and associated volatility of all economies.

Regarding the rate of inflation, the log difference computation (prefix with DL) ${ }^{3}$ implies dealing with monthly changes whose averages range between 0.12 and 0.19 percentage points ( $\mathrm{pp}$ henceforth) in most cases. At the two extremes, we find Japan and Spain. For years trapped in the 'lost decade', Japan has a minimal 0.03 pp increase in inflation on average, while in Spain attains $0.21 \mathrm{pp}$. Spain is, by far, the economy with the largest volatility also in inflation.

\subsection{Univariate analysis}

Methodologically, the DY spillover index depends upon how the underlying estimated VAR system is modeled. This implies that the integrated order of the

\footnotetext{
${ }^{3}$ We employ the prefix notation 'L' and 'DL' representing the logarithm and log-difference operators, respectively.
} 
endogenous variables has utmost importance. If the variables of the VAR are non-stationary or contain unit roots, then it is necessary to consider whether they are cointegrated or not. As shown in DY (2015), omitting the cointegrating relationship while it holds could lead to a downward bias in the computation of the spillover index. We consider standard univariate unit root tests for individual series and unit root tests in a panel context such as Levin, Lin, and Chu (2002) (LLC), Im, Pesaran, and Shin (2003) (IPS), and Breitung (2001). This array of tests allows us to check for robustness checks and reach a solid conclusion on the degree of integration of the variables.

Tables 2 and 3 report the tests mentioned above of UNRATE and LCPI, respectively. It is shown that, in general, the null of unit root cannot be rejected either for UNRATE nor LCPI in any of the eight economies considered. However, we observe weak evidence of (trend) stationarity for the German consumer price index and the US unemployment rate, while nonlinear tests (Kapetanios et al., 2003; Kruse, 2011) provide inconclusive unit root evidence on the US and French unemployment rates.

To substantiate the previous conclusion, we conduct a battery of panel unit root tests. As reported in Table 4, all three tests-IPS, LLC, and Breitung-provide strong evidence that the null hypothesis of a unit root cannot be rejected. IPS tests indicate each time series has a unit root per se; meanwhile, the LLC and Breitung test suggests that there could be a common unit root in the consumer price indices of the eight countries in the sample. Simply put, there is unarguably unit root evidence for the unemployment rate and the consumer price index of the G7 countries and Spain over the period from 1991 to 2019. Following our previous discussion, note that these results are compatible with the hysteresis hypothesis. What is crucial for our research, however, is the conclusion that cointegration has to be considered in the estimation of the VAR model on which the DY measurements of UNRATE and LCPI volatility spillovers will be computed.

For the case of the industrial production data in the G7 countries, DY (2015, ch.8) reports a downward bias in the computation of the spillover if their cointegration relationships are omitted. Hence, given the previous unit root evidence, it is crucial to ensure that a long-run relationship does indeed exist among the data series in the same VAR system. We thus apply Johansen's (1991) cointegration tests on UNRATE and LCPI with different model specifications and lag lengths. Table 5 summarizes the outcome of this analysis.

Regarding the unemployment rate, the cointegration order varies from 1 to 5 for the trace criteria, depending upon the lag length selected (running from 1 to 11). The max eigenvalue statistics, however, suggest the maximum order of 3 . The tests are robust regardless of the presence of an unconstrained constant variable in the vector error correction model (VECM). In turn, the consumer price index consistently shows a cointegration order between 3 and 5 .

In addition, Fig. 1 validates whether the time series of unemployment "Granger causes" one another (left-hand-side panel) and whether the time series of inflation "Granger causes" one another (middle panel). Recall that the statement "Granger causes" does not necessarily imply that it is the effect of or the result of. What Fig. 1 shows is the proof that the trajectories of the unemployment rate series on the one 


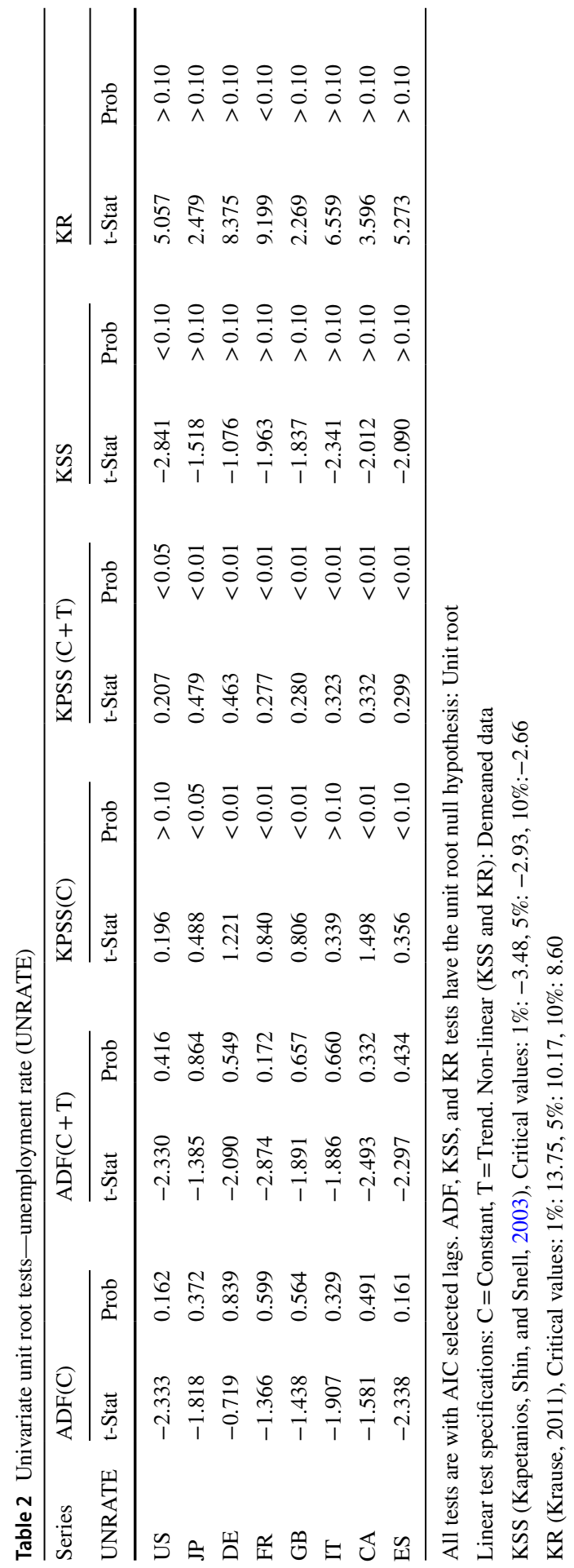




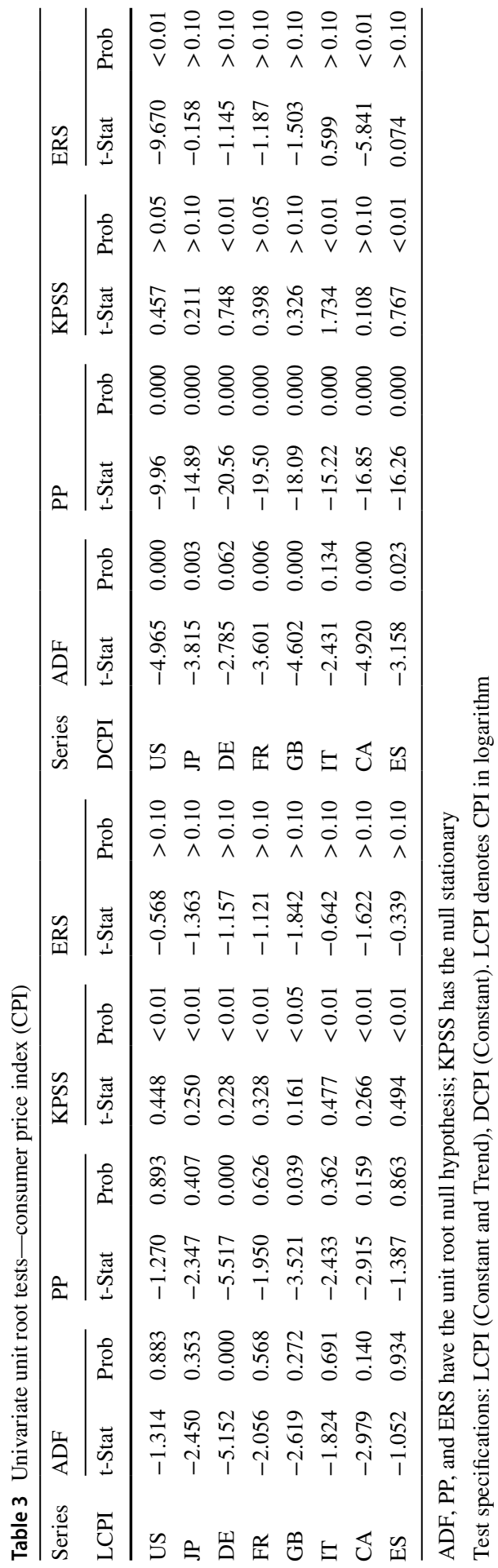


Table 4 Panel unit root tests

\begin{tabular}{lllllllllll}
\hline Panel Method & IPS $(\mathrm{C})$ & & \multicolumn{2}{l}{ IPS $(\mathrm{C}+\mathrm{T})$} & LLC $(\mathrm{C})$ & & \multicolumn{2}{l}{ LLC $(\mathrm{C}+\mathrm{T})$} & \multicolumn{2}{c}{ BR $(\mathrm{C}+\mathrm{T})$} \\
\hline Variable & t-Stat & Prob & t-Stat & Prob & t-Stat & Prob & t-Stat & Prob & t-Stat & Prob \\
UNRATE & 0.491 & 0.688 & 0.265 & 0.605 & -0.151 & 0.440 & -1.859 & 0.032 & -0.248 & 0.406 \\
LCPI & - & - & -0.937 & 0.744 & - & - & -3.289 & 0.001 & -2.587 & 0.995
\end{tabular}

IPS = Im, Pesaran, Shin (2003); LLC=Levin, Lin, and Chu (2002); BR=Breitung (2001)

LLC and Breitung null hypothesis: Common Unit root; Test specifications: $\mathrm{C}=\mathrm{Constant}$, $\mathrm{T}=\mathrm{Trend}$; $\mathrm{SIC}$ lag selection

Table 5 Cointegration tests

\begin{tabular}{|c|c|c|c|c|c|c|c|c|}
\hline \multirow{2}{*}{$\begin{array}{l}\text { Method } \\
\text { Variable }\end{array}$} & \multicolumn{2}{|c|}{ Test specification for C-matrix } & \multicolumn{3}{|c|}{ Trace: $\operatorname{rank}(\mathrm{C})$} & \multicolumn{3}{|c|}{$\begin{array}{l}\text { Max Eigenvalues: } \\
\text { rank (C) }\end{array}$} \\
\hline & $H 1^{*}: A\left(B^{\prime} y_{t-1}+c_{0}\right)$ & $H 1: A\left(B^{\prime} y_{t-1}+c_{0}\right)+c_{1}$ & Lags & Min & $\operatorname{Max}$ & Lags & Min & $\operatorname{Max}$ \\
\hline UNRATE & Yes & Yes & {$[1: 11]$} & 1 & 5 & {$[1: 11]$} & 1 & 3 \\
\hline LCPI & No & Yes & {$[1: 11]$} & 3 & 5 & {$[1: 11]$} & 3 & 5 \\
\hline
\end{tabular}

VEC(q) model $\Delta \mathrm{y}_{\mathrm{t}}=C y_{t-1}+B_{1} \Delta y_{t-1}+\cdots+B_{q} \Delta \mathrm{y}_{t-q}+D X+\epsilon_{t} \cdot \operatorname{rank}(C)$ refers to the rank of matrix $C \equiv A B^{\prime}$

\section{Unemployment Rate}

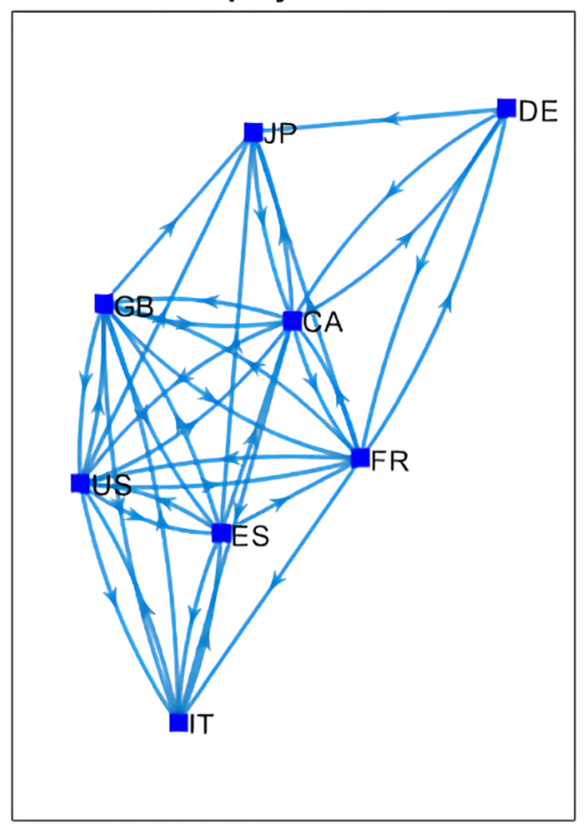

Inflation Rate

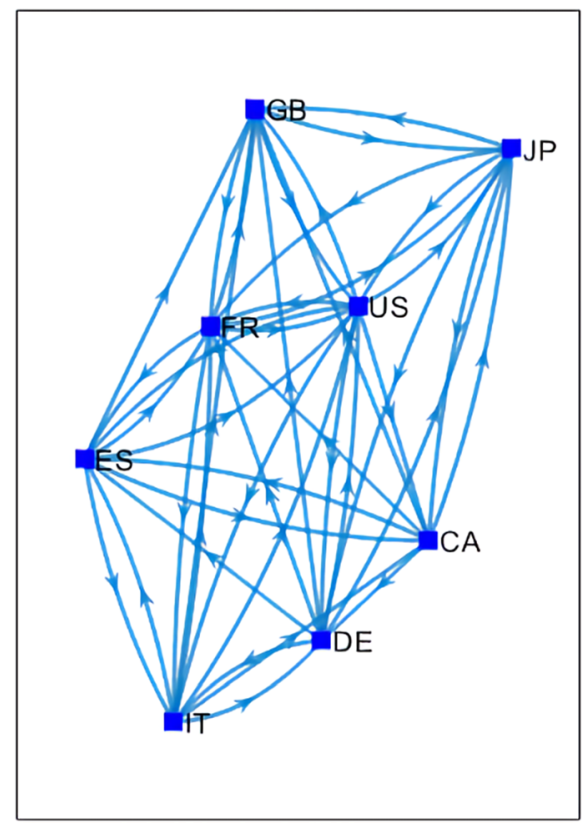

Fig. 1 Granger-causality network graph. Note The arrow direction represents the Granger-causality direction 
Table 6 Unemployment spillovers

\begin{tabular}{lrrrrrrrrr}
\hline Country & \multicolumn{1}{l}{ US } & \multicolumn{1}{l}{ JP } & \multicolumn{1}{l}{ DE } & \multicolumn{1}{l}{ FR } & \multicolumn{1}{l}{ GB } & \multicolumn{1}{l}{ IT } & CA & ES & From others \\
\hline US & 63.97 & 5.35 & 4.36 & 8.70 & 2.17 & 0.19 & 4.31 & 10.94 & 36.03 \\
JP & 14.03 & 47.00 & 5.06 & 3.92 & 0.14 & 14.42 & 2.57 & 12.86 & 53.00 \\
DE & 4.66 & 1.30 & 73.04 & 4.93 & 0.06 & 0.64 & 5.98 & 9.39 & 26.96 \\
FR & 9.99 & 0.23 & 4.15 & 52.44 & 4.28 & 4.97 & 7.44 & 16.50 & 47.56 \\
GB & 18.32 & 0.06 & 0.74 & 11.86 & 53.53 & 0.18 & 0.65 & 14.66 & 46.47 \\
IT & 1.01 & 3.94 & 7.58 & 7.93 & 2.61 & 60.55 & 0.20 & 16.17 & 39.45 \\
CA & 24.10 & 0.20 & 8.02 & 15.76 & 2.00 & 0.09 & 42.85 & 6.97 & 57.15 \\
ES & 6.68 & 0.20 & 0.65 & 4.46 & 11.27 & 3.90 & 0.67 & 72.18 & 27.82 \\
To others & 78.79 & 11.29 & 30.57 & 57.54 & 22.54 & 24.39 & 21.82 & 87.50 & 41.81 \\
NET & 42.77 & -41.72 & 3.61 & 9.98 & -23.93 & -15.06 & -35.33 & 59.68 & \\
\hline & & & & & & & & &
\end{tabular}

side, and the trajectories of the rate of inflation on the other, help in predicting the trajectories, respectively, of any particular unemployment or inflation rate series.

The direction of the influences is conveyed through the arrows pictured in the figure. It thus appears that there is direct mutual influence among all processes, which can be interpreted as the first rough evidence of connectedness across countries. It is also worth noting that the density of each Granger-causality graph denotes the strength of the connected grid. The more edges connecting any two countries are pictured, the larger the mutual impacts are and, consequently, the more spillover effects will be found. From Fig. 1, it is not unreasonable to expect that fundamental shocks to the consumer price index will propagate more intensively than those hitting the unemployment rate in the G7 economies and Spain.

\section{Results and discussions}

\subsection{General appraisal}

We estimate two VEC models with a single cointegration rank and one-year lags for fully uncovering the system's dynamics. ${ }^{4}$ We find total connectedness (or total spillovers) to be larger when computed for a nominal variable such as prices (58.28\% shown in Table 7) than when computed for a real variable such as the rate of unemployment (41.81\% shown in Table 6). This result is consistent with the fact that consumer prices are subject to global pressures in perpetual search of market share gains. Hence, the more is output determined as a global scale through growing global value chain processes, the more intertwined the markets are, and the more likely will the impact of country-specific shocks on prices spread out internationally. In contrast, the unemployment rate is more representative of the whole economy

\footnotetext{
4 As in Diebold and Yilmaz (2015, ch.8), we disregard the possibility of exploring higher cointegration ranks.
} 
(in particular, of the dominant services sector, which in the G7 countries is a less globalized sector than its industrial counterpart is). Given that a significant part of the services sector (e.g., public sector related services) is not much exposed to international influences, lower connectedness in unemployment than in prices is to be expected. We also find it plausible that price connectedness lies well below financial connectedness within the US financial sector, which is 78\% (DY, 2014).

For prices, directional spread to others ranges from $113.90 \%$ in the US to $14.04 \%$ in the UK (19.70\% in Japan). Despite the gap is also large in the case of unemployment, country values range within a narrower interval between $87.50 \%$ in Spain and $11.29 \%$ in Japan. The fact that spreads to others are larger in the nominal than in the real variable suggests that local/national nominal shocks have a larger potential to spill over to other economies. This is probably reflecting that price adjustments can be implemented more quickly than quantity adjustments, in this case, in response to external spillovers.

The ample intervals in the directional spread to others contrast with the intervals obtained for the directional spread from others. These are much narrower and range from $63.63 \%$ in Germany to $43.04 \%$ in Japan in the case of consumer prices, and between $57.15 \%$ in Canada and $27.82 \%$ in Spain in the case of unemployment. Therefore, no matter whether the level of connectedness is high (prices) or low (unemployment), directional spread to others is much more diverse than directional spread from others.

\subsection{Country patterns}

The general pattern just described conceals what we believe is an interesting feature by countries. In particular, a situation of positive current account balances seems to be associated with a prominence of the directional spread from others over directional spread to others. This is clearly the case in Japan, Germany, and Italy both for unemployment and prices. In contrast, in economies with a negative current account balance across time, directional spread to others dominates directional spread from others. This is clearly the case of Spain and the USA, where the current balance has traditionally evolved on the negative side, and it is the case of France, where the current account balance used to be positive in the 1990s, deteriorated in the early 2000s, and became negative ever since 2006. The fact that Canada, and to some extent the $\mathrm{UK}$, diverges from the previous pattern is probably related to the extremely close connection between these economies and the US. We further scrutinize this issue below.

Before, let us notice that all pairwise or bilateral connectedness across countries is lower for unemployment than for inflation. Regarding unemployment, the exceptions lie in all diagonal terms, which reflect own connectedness. All terms representative of own connectedness are clearly the largest elements in the table implying that unemployment volatility is, above all, an internal matter. Still, some economies display large directional connectedness. In particular, Spain, followed by the USA, appears as the economy with the largest directional connectedness to others. This is the outcome of a very particular labor market, very sensitive to all types of shocks 
because of its largest share of temporary work among the OECD countries. This implies that Spain is a great generator of volatility spillovers arising from shocks in unemployment.

As noted, another interesting feature is the high pairwise connectedness between the USA, and Canada and the UK. It attains $18.32 \%$ from the USA to the UK, while it reaches $24.10 \%$ from the USA to Canada. These values confirm the close relationship between these three economies from the point of view of their unemployment connectedness and reinforce, from a new perspective in the literature, the notion of an Anglo-Saxon model in terms of the labor market (and social-related matters linked to the welfare state).

Germany appears as the most self-contained labor market with own connectedness attaining $73.04 \%$. It is followed by Spain $(72.18 \%$ ), which is also characterized by the second to the lowest directional connectedness from others, but the highest one to others. In particular, pairwise connectedness is relatively large when running from Spain to its European partners (Italy, 16.17\%; the UK, 14.66\%; and France, $16.50 \%$ ). At the other extreme, Japan, with a well-known particular system of labor relations has the lowest directional connectedness to others.

Overall, the message accruing from these results is that, even though unemployment volatility is essentially an internal matter, some economies (USA, Spain) are strong net transmitters of volatility. This implies that labor market policies, which are generally regarded as a pure national matter, should probably deserve some supranational coordination. For example, within the European Monetary Union, this view would probably be endorsed by economies such as Germany or Italy, which are net receivers of volatility spillovers from unemployment shocks in other economies such as Spain.

Regarding prices, it is interesting to observe that the USA is the economy with a bigger degree of connectedness in both directions (it is first in the ranking to others, and very close to the first in the ranking from others). We believe this is to be associated with the role of the USD as a universal currency. Relatedly, pairwise connectedness between the USA and Canada is the highest one. From the US to Canada, it amounts to $25.27 \%$, while it is $12.26 \%$ from Canada to the US. This confirms the view that these economies are closely intertwined also with respect to their price behavior. At the other extreme, Japan, and then the UK, has the smallest degree of connectedness among the studied economies in both directions (and note, also, that Japan has the largest level of own connectedness). We believe this reflects the idiosyncratic management of their monetary policy. Japan, for obvious reasons, since it has been trapped during most of the examined period in what initially was thought to be a "Lost decade". In the case of the UK, it is the largest economy belonging to the European Union (during the sample period), without being in the Eurozone.

\subsection{Implications for the Phillips curve trade-off}

One main feature of the trade-off between the rates of inflation and unemployment is its short-run relevance. For essentially the same sample of countries, Pham and Sala (2019) showed that the short impact of fiscal shocks generates different responses in 
output and unemployment, leading to large immediate trade-offs. This evidence is complemented by our analysis here.

Connectedness measures volatility spillovers in response to a shock. Although the measure of connectedness in DY (2015) is agnostic on how it arises, in order to interpret its consequences for the Phillips curve trade-off let us think on an oil price shock that pushes up prices and unemployment. In such situation, our findings point to larger total spillovers in CPI than in unemployment. This implies that, in relative terms, there is more volatility accruing from abroad in CPI than in unemployment, with immediate consequences for the Philips curve trade-off. Given the asymmetric increased volatility in both variables (in response to a shock of the same magnitude), the trade-off becomes blurred and biased. Blurred because in a situation of increased volatility, the usefulness of the trade-off for forecasting purposes erodes. Biased because connectedness is substantially larger in prices than in unemployment.

Lepetit (2020) shows that in the presence of unemployment asymmetries, ${ }^{5}$ a relationship exists between inflation volatility and average unemployment. This channel of transmission implies that connectedness may well have an effect on the sacrifice ratio since the opportunity cost of reducing unemployment, which becomes higher in recessions in terms of inflation, may be exacerbated by the higher imported price volatility (relatively to the also enhanced imported unemployment volatility). It is in this way that connectedness appears as an enhancer factor of short-run Phillips curve trade-offs during recessions.

Let us now perform the analogous reasoning in the event of a positive shock in which prices and unemployment decrease. Given that connectedness is larger in prices than in unemployment, there is more imported volatility along the downward move in prices, than it is along the downward move in unemployment. Given Lepetit's (2020) transmission channel, the implication of connectedness for the Phillips curve trade-off, in this case, is the opposite. Now, the sacrifice ratio is reduced since the cost to bring unemployment down is lower in terms of inflation. It thus follows that connectedness is likely to limit the extent of the Phillips curve trade-off during expansions. ${ }^{6}$

If connectedness acts as an enhancer of short-run Phillips curve trade-offs during recessions and as diminisher of such trade-offs in expansions, there is a double-sided incentive for policy makers to increase cross-country coordination. First, to avoid spillovers from other country-specific shocks and second to avoid larger sacrifice ratios when having to bring inflation down in periods of economic downturns.

\footnotetext{
5 Unemployment asymmetries arise as follows: "In an expansion, the impact on unemployment of an increase in the job-finding probability is dampened by the fact that the pool of job seekers is shrinking. In a recession, the impact on unemployment of a decrease in the job-finding probability is amplified by the fact that the pool of job seekers is expanding. In other words, in a search and matching model of the labor market, unemployment losses in recessions tend to be greater than unemployment gains in expansions" [Lepetit (2020), p. 1].

6 This connects with the evidence provided by Karlsson and Österholm (2020) in support of Phillips curve time-varying parameters and stochastic volatility. This evidence leads them to call for frameworks, like ours, "that allow for time variation in the relationships between macroeconomic variables as well as the variance of the shocks that hit the economy" [Karlsson and Österholm (2020), p. 2559].
} 
Table 8 Phillips curve spillovers

\begin{tabular}{lrrrrrrrrr}
\hline Country & \multicolumn{1}{l}{ US } & \multicolumn{1}{l}{ JP } & \multicolumn{1}{l}{ DE } & \multicolumn{1}{l}{ FR } & \multicolumn{1}{l}{ GB } & \multicolumn{1}{l}{ IT } & CA & ES & From others \\
\hline US & 39.47 & 2.56 & 7.76 & 10.86 & 5.99 & 4.21 & 16.81 & 12.35 & 60.53 \\
JP & 6.71 & 68.12 & 6.19 & 6.33 & 3.03 & 2.17 & 4.19 & 3.25 & 31.88 \\
DE & 9.71 & 2.20 & 50.04 & 15.62 & 4.28 & 6.30 & 3.68 & 8.18 & 49.96 \\
FR & 13.50 & 1.12 & 14.08 & 40.61 & 4.07 & 8.17 & 8.89 & 9.55 & 59.39 \\
GB & 9.57 & 3.85 & 6.85 & 7.85 & 56.81 & 3.11 & 5.82 & 6.13 & 43.19 \\
IT & 8.10 & 2.15 & 7.03 & 9.65 & 3.33 & 51.59 & 5.51 & 12.63 & 48.41 \\
CA & 21.62 & 1.28 & 3.23 & 9.00 & 5.56 & 4.66 & 45.39 & 9.27 & 54.61 \\
ES & 15.60 & 1.82 & 7.21 & 9.61 & 4.19 & 7.90 & 7.52 & 46.14 & 53.86 \\
To others & 84.81 & 14.97 & 52.36 & 68.93 & 30.45 & 36.53 & 52.43 & 61.37 & 50.23 \\
NET & 24.28 & -16.90 & 2.40 & 9.54 & -12.74 & -11.89 & -2.19 & 7.51 & \\
\hline
\end{tabular}

\subsection{Direct Phillips curve trade-offs}

Given the previous evidence, it is worth checking for connectedness directly arising from the countries' Phillips curve trade-off. The Phillips Curve can be defined allowing both the 'nature' of the economy $\left(u_{t}^{*}\right)$ and the corresponding unemployment gap $\left(\right.$ ugap $\left._{t}\right)$ to change over time (see e.g., Laubach, 2001; Fabiani and Mestre, 2004):

$$
\begin{gathered}
\pi_{t}=\alpha(L) \pi_{t-1}-\beta(L)\left(u_{t}-u_{t}^{*}\right)+\epsilon_{t} \\
u_{t}=u_{t}^{*}+\operatorname{ugap}_{t} \\
u_{t}^{*}=u_{t-1}^{*}+\eta_{t} \\
\operatorname{ugap}_{t}=\rho \cdot \operatorname{ugap}_{t-1}+\omega_{t}
\end{gathered}
$$

Note that $u_{t}^{*}$ is usually referred as the non-accelerating natural rate of unemployment (NAIRU), while ugap is the by-product of the Kalman filter process; $\epsilon_{t} \sim N\left(0, \sigma_{\epsilon}^{2}\right) ; \eta_{t} \sim N\left(0, \sigma_{\eta}^{2}\right)$, and $\omega_{t} \sim N\left(0, \sigma_{\omega}^{2}\right)$ denote error terms; and $E\left(\eta_{t}, \omega_{t}\right)=0$. The error term $\epsilon_{t}$ contains the Phillips Curve's residuals needed to perform DY's decomposition. We estimate model (1) using the multivariate Kalman filter and compute again connectedness, this time directly over the Phillips Curve's residuals. As shown in Table 8, results are consistent with the previous analysis over unemployment and prices.

Own connectedness lies roughly in between the one uncovered for unemployment and the one for prices, although it is generally closer to the latter. Countryspecific patterns, such as the influence of the USA on Canada, or the largest ownconnectedness displayed by Japan (68.1), are also present. Directional spread to others is also lying in between the ones for unemployment and prices, being closer to the latter with the exception is Japan where it is below (31.88). This 
(A) DY Rolling Index of UNRATE

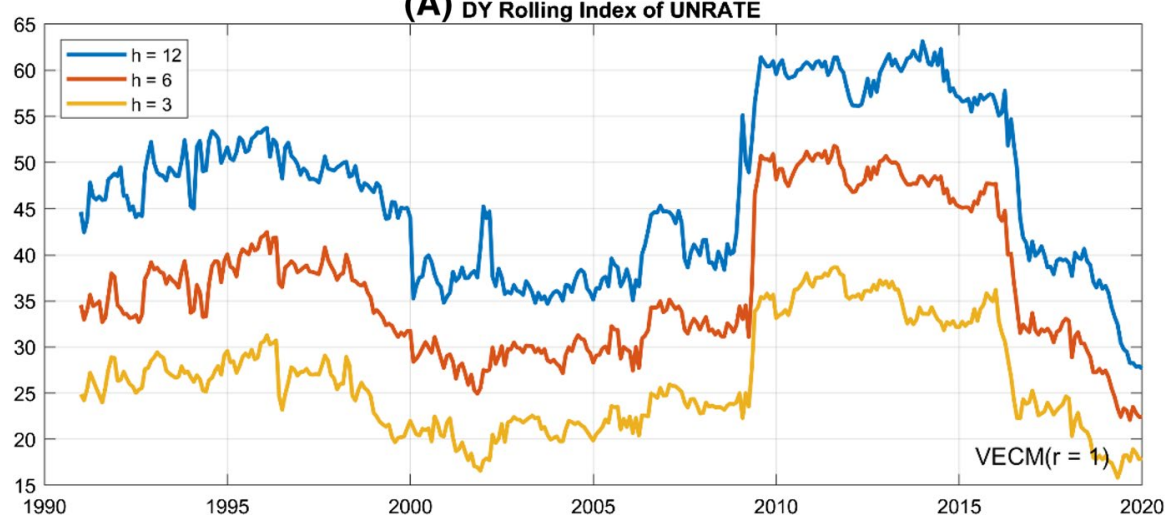

(B) DY Rolling Index of LCPI

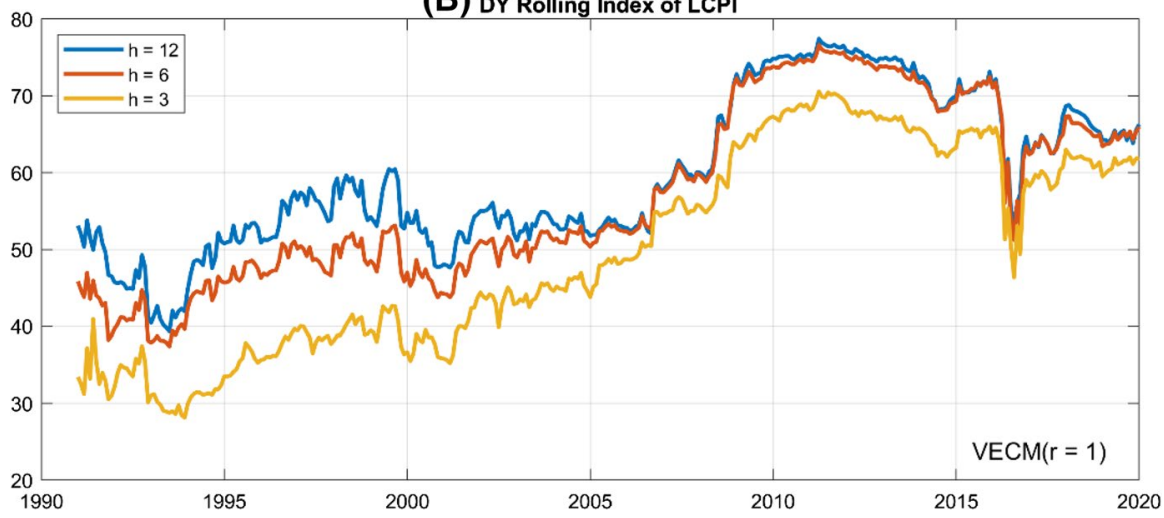

Fig. 2 Dynamic spillover indices. Note Window size $=96$ months. VAR $(\mathrm{p}=3)$ and $\mathrm{h}=3,6,12$ GFEVD horizons

pattern is also the common one for the directional spread from others, but is in contrast to net spillovers, which are smaller in all cases.

\section{Time-varying connectedness}

Figure 2 pictures volatility spillovers defined as the sum of all variance decomposition 'contributions to others' from Tables 6 and 7, respectively, estimated using a time window of 96 months based on a 3-, 6-, and 12-month generalized forecast error variance decomposition (GFEVD). ${ }^{7}$

\footnotetext{
${ }^{7}$ We use official data sources to extend the dataset to have the presample period from 1983 to 1990 , so that the first time-varying point estimate starts in January 1991. Details and the corresponding time series are available upon request from the authors.
} 
Table 7 Consumer price spillovers

\begin{tabular}{lrrrrrrrrl}
\hline Country & \multicolumn{1}{l}{ US } & \multicolumn{1}{l}{ JP } & \multicolumn{1}{l}{ DE } & \multicolumn{1}{l}{ FR } & \multicolumn{1}{l}{ GB } & \multicolumn{1}{l}{ IT } & CA & ES & From others \\
\hline US & 37.49 & 2.19 & 8.42 & 12.81 & 0.97 & 5.16 & 12.26 & 20.70 & 62.51 \\
JP & 14.91 & 56.96 & 11.94 & 5.53 & 2.73 & 1.20 & 5.96 & 0.77 & 43.04 \\
DE & 21.43 & 0.84 & 36.37 & 15.83 & 2.94 & 9.46 & 3.40 & 9.72 & 63.63 \\
FR & 15.08 & 4.19 & 8.79 & 37.12 & 1.26 & 10.45 & 8.52 & 14.59 & 62.88 \\
GB & 9.68 & 2.25 & 8.33 & 10.12 & 43.81 & 6.96 & 2.14 & 16.71 & 56.19 \\
IT & 10.14 & 1.57 & 3.18 & 12.01 & 1.51 & 42.90 & 3.93 & 24.77 & 57.10 \\
CA & 25.27 & 1.80 & 1.64 & 11.49 & 0.47 & 7.44 & 41.27 & 10.63 & 58.73 \\
ES & 17.39 & 5.37 & 4.48 & 12.20 & 4.17 & 14.43 & 4.10 & 37.87 & 62.13 \\
To others & 113.90 & 18.21 & 46.78 & 80.00 & 14.04 & 55.10 & 40.30 & 97.88 & 58.28 \\
NET & 51.39 & -24.83 & -16.84 & 17.12 & -42.15 & -2.00 & -18.44 & 35.75 & \\
\hline
\end{tabular}

The pattern followed is similar across GFEVD horizons. In general, the longer the horizon (i.e., higher $h$ ) the larger connectedness is. In the case of inflation, however, there is a negligible gap between the 6- and 12-month horizons implying that most adjustments take place over the 3-month horizon.

The first episode in which connectedness in price trends upward starts in 1994, once the European Monetary System (EMS) overcomes the 1992/1993 crisis and the road to the European and Monetary Unions (UME) is cleared. The degree of connectedness in prices kept increasing after 2001, in parallel to the enhanced globalization brought by the changes resulting from the inclusion of China in the World Trade Organization (WTO). The aftermath of the GFC puts a halt on this rise. It is interesting to observe that volatility spillovers seem to have reached a relatively stable plateau in the final part of the sample period of analysis, of around 70\% (with $\mathrm{h}=6$ and $\mathrm{h}=12$ ). In clear contrast, connectedness in unemployment has returned to its level before the GFC.

Indeed, volatility spillovers in unemployment display a very marked change around the GFC. It is a period in which connectedness increases approximately by half, from 40 to $60 \%$ (with $h=12$ ), to return to $40 \%$ once the financial shock vanishes. This result is the real-side counterpart of the rise in financial firms' connectedness documented by DY (2015) during the GFC.

In any case, Fig. 2 confirms that price connectedness is larger than unemployment connectedness even in a dynamic analysis such as the one provided by the rolling indices. Figure 3 checks the behavior of spillovers when computed over the Phillips curve residuals $\left(\epsilon_{t}\right)$ and the unemployment gap residuals $\left(\omega_{t}\right)$. Again, we observe smaller spillovers when these are associated to the cross-country influence of unemployment-related shocks, and confirm the sudden, temporary and large impact of the GFC over the labor market.

A final remark connects our results in terms of the asymmetric impact of connectedness on the Phillips curve, with those in terms of the extraordinary spillover volatility caused by the GFC. Our results provide a quantitative approximation to the degree of extra uncertainty (volatility) that surrounds the relationship between inflation and unemployment in times of economic turmoil. This reaches 


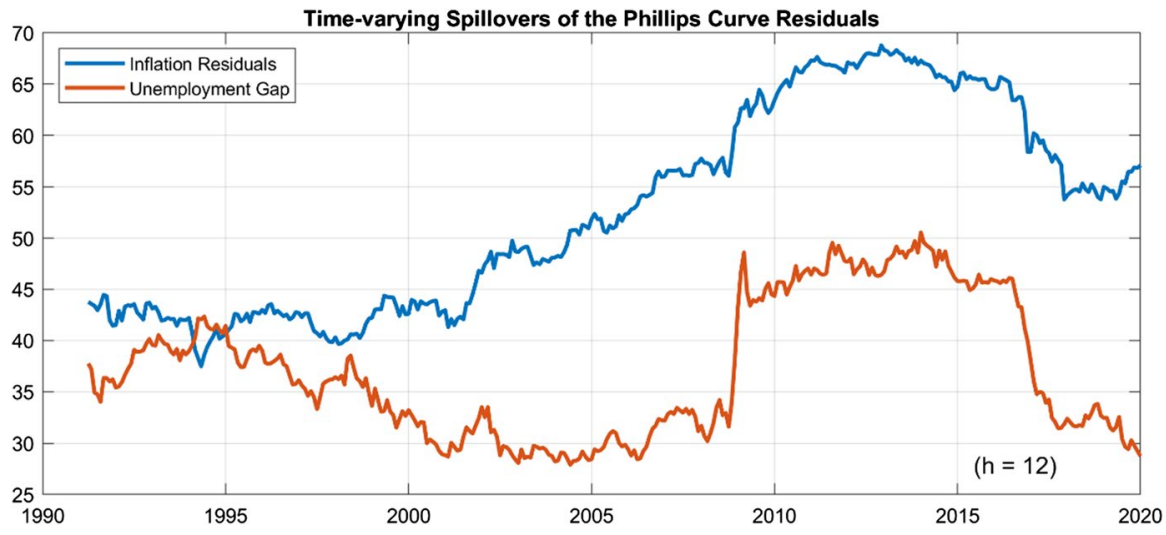

Fig. 3 Phillips curve and unemployment gap dynamic spillover indices. Note Window size $=96$ months. $\operatorname{VAR}(\mathrm{p}=3)$ and $\mathrm{h}=12$ GFEVD horizons

around 20 percentage points with $\mathrm{h}=6$ and $\mathrm{h}=12$ for unemployment and inflation (Fig. 2), somewhat less when the Phillips Curves is directly assessed (Fig. 3), but again close this value when only the labor market is checked (Fig. 3). We believe this finding should provide a further incentive for stimulating policy coordination across countries and trade blocks.

Of course, shocks will always be unexpected by definition. However, we know that on the nominal side, globalization (global financial markets, global value chains) have pushed connectedness to unprecedented high record levels. This has brought a new scenario for the conduct of the monetary policy, which Rogoff (2007) associated with the volatility of asset prices. Rogoff's reasoning aligns with previous findings in the literature on connectedness and our own findings. On the real side, we know that economic convergence across economies could help to prevent major increases in volatility spillovers caused by shocks, as the ones just highlighted, while coordination in the reaction could help to bring them down more effectively in the aftermath of such shocks. We believe this is particularly relevant for a socially sensitive issue, such as unemployment.

Figure 3 shows the correlation over time between the volatility spillovers of unemployment and inflation. These spillovers are basically uncorrelated until 2010 (with some negative correlation in the 1990s) when a positive and significant correlation around 0.5 appears. This co-movement is the result of the simultaneous jump in unemployment and inflation connectedness depicted in Fig. 2, which is to be ascribed to the consequences of the GFC.

Overall, exploration of time-varying connectedness uncovers a new relevant transmission channel by which the economies' response to country-specific shocks becomes an additional transmission channel for the effects of common shocks. That is, the spread of volatility spillovers of country-specific shocks is magnified in periods of global economic turmoil such as the one experienced with the GFC. This is our reading of the increased level of connectedness across 
Dynamic Spillover Correlation $\rho_{\text {DY(UNRATE, CPI) }}$
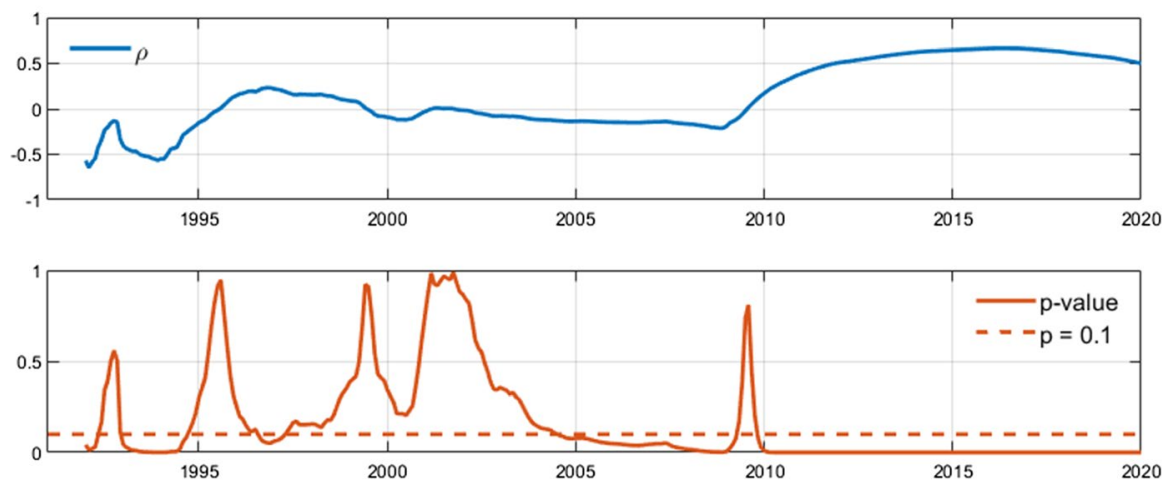

Fig. 4 Dynamic spillover correlation

Dynamic Net Spillover of UNRATE $(h=12)$
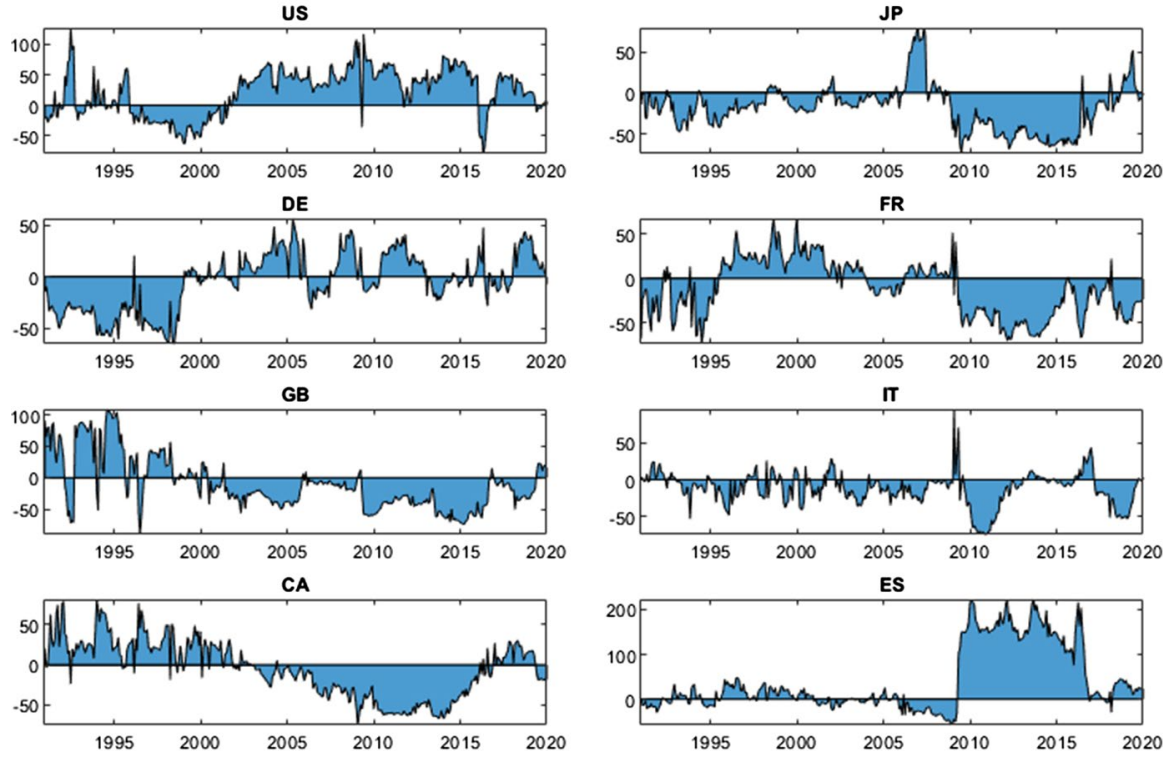

Fig. 5 Rolling net spillover of unemployment rate

countries in all variables (as depicted in Fig. 2) and the increased correlation between connectedness in unemployment and inflation (as shown in Fig. 4).

Figures 5 and 6 provide country-specific information on the evolution of the net volatility spillovers resulting, respectively, from shocks in unemployment and inflation. Periods with positive (negative) values indicate that directional spread to (from) others overcomes directional spreads from (to) others. The trace of the GFC can be identified in the majority of cases and reinforces our previous 
Dynamic Net Spillover of LCPI $(h=12)$
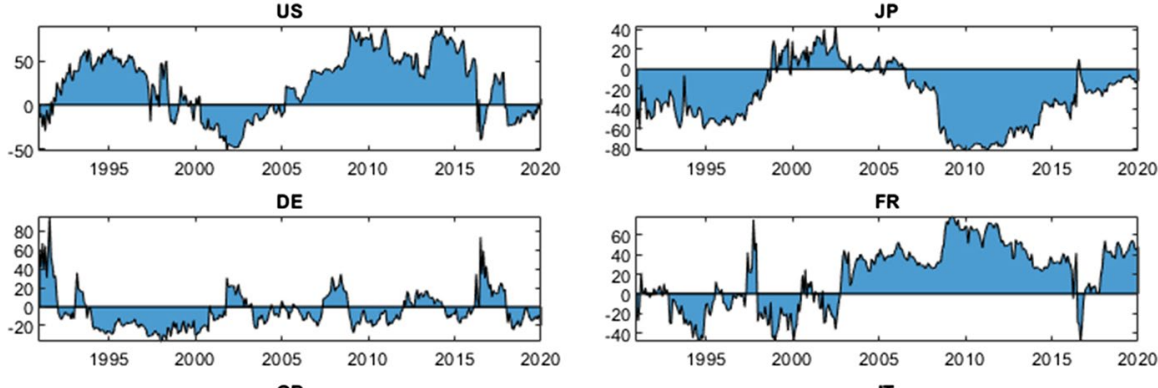

GB

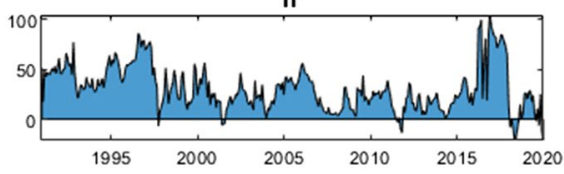

CA
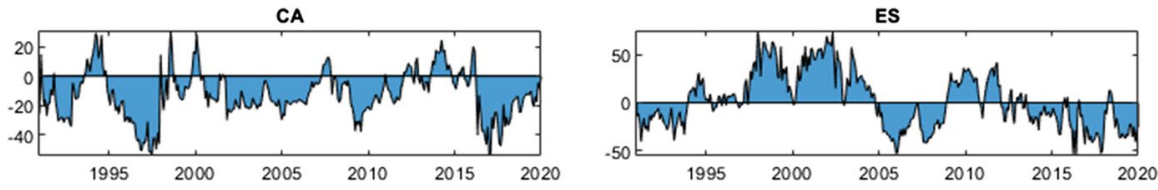

Fig. 6 Rolling net spillover of consumer price index

conclusion at a country-specific level. The difference is that Figs. 5 and 6 allows us to distinguish the direction of the influence that connects the economies.

Looking at the Anglo-Saxon countries, the first specific feature is the complementary picture we obtain in the US - with net directional spread to others in most of the sample period - with respect to the picture for both the UK and Canada-which feature net directional spread from others. This holds in terms of both unemployment and inflation. In the case of the Continental European economies, Germany behaves unlike France, Italy, and Spain, with net directional spread to others after the setup of the European Monetary Union (EMU) in 1999 in the case of unemployment, and a neutral spread in the case of inflation. In contrast, France and Italy move from net positive to net negative spreads after the EMU in the case of unemployment, while they have net volatility spillovers to others in the case of inflation. In the case of Japan, directional spreads from others are prominent in both unemployment and inflation. In a nutshell, Germany and Japan (and the UK and Canada) do not spread out the consequences of the country-specific shocks they experience on inflation, in clear contrast to the US, France, and Italy (and Spain before the EMU).

Overall, Germany is the only economy where the GFC seems to have been innocuous in changing the spread of volatility spillovers in net terms. 
Table 9 Connectedness under alternative normalization rules

Panel A: UNRATE

\begin{tabular}{|c|c|c|c|c|c|c|c|}
\hline & \multicolumn{3}{|c|}{ From others } & & \multicolumn{3}{|l|}{ NET } \\
\hline & Row Sum & Max Row & Spectral & & Row Sum & Max Row & Spectral \\
\hline US & 57.15 & 56.50 & 63.86 & ES & 59.68 & 54.29 & 61.35 \\
\hline JP & 53.00 & 46.80 & 52.89 & US & 42.77 & 38.58 & 43.60 \\
\hline $\mathrm{DE}$ & 47.56 & 47.56 & 53.75 & FR & 9.98 & 3.31 & 3.74 \\
\hline FR & 46.47 & 38.56 & 43.58 & $\mathrm{DE}$ & 3.61 & 5.48 & 6.19 \\
\hline GB & 39.45 & 31.11 & 35.16 & IT & -15.06 & -9.22 & -10.43 \\
\hline IT & 36.03 & 33.02 & 37.32 & GB & -23.93 & -18.70 & -21.13 \\
\hline $\mathrm{CA}$ & 27.82 & 23.15 & 26.16 & $\mathrm{CA}$ & -35.33 & -36.66 & -41.43 \\
\hline ES & 26.96 & 22.21 & 25.10 & JP & -41.72 & -37.07 & -41.89 \\
\hline Spillover index & 41.81 & 37.36 & 42.23 & & - & - & - \\
\hline
\end{tabular}

Panel B: LCPI

\begin{tabular}{|c|c|c|c|c|c|c|c|}
\hline & \multicolumn{3}{|c|}{ From others } & & \multicolumn{3}{|l|}{ NET } \\
\hline & Row sum & Max row & Spectral & & Row sum & $\max$ rowz & Spectral \\
\hline $\mathrm{DE}$ & 63.63 & 52.89 & 59.13 & US & 51.39 & 36.60 & 40.92 \\
\hline FR & 62.88 & 62.88 & 70.29 & $\mathrm{ES}$ & 35.75 & 39.71 & 44.39 \\
\hline US & 62.51 & 61.34 & 68.57 & FR & 17.12 & 6.00 & 6.71 \\
\hline ES & 62.13 & 49.03 & 54.81 & IT & -2.00 & 1.57 & 1.76 \\
\hline CA & 58.73 & 58.44 & 65.33 & $\mathrm{DE}$ & -16.84 & -13.30 & -14.87 \\
\hline IT & 57.10 & 47.28 & 52.85 & CA & -18.44 & -22.94 & -25.65 \\
\hline GB & 56.19 & 47.68 & 53.30 & JP & -24.83 & -11.37 & -12.71 \\
\hline JP & 43.04 & 27.64 & 30.90 & GB & -42.15 & -36.27 & -40.54 \\
\hline Spillover index & 58.28 & 50.90 & 56.90 & & - & - & - \\
\hline
\end{tabular}

\section{Sensitivity analysis through different normalization rules}

The computation of spillovers requires a normalization scheme to facilitate interpretation. The traditional scheme is a row sum normalization rule by DY (2012) called "Row Sum" (see Equation (A6) in the Online Appendix). Caloia et al. (2019), however, explain that different normalization rules have the potential to lead to a different interpretation of the results. As a consequence, it is important to check the robustness of our results when filtered by different normalization schemes such as the extra ones proposed by Caloia et al. (2019). These are scalarbased normalization schemes in which the denominator of Equation (A6) is substituted by some scalar. In the first scheme, this scalar is the maximum value of the row sum (it could also be of the column sum), while in the second scheme, the scalar is the maximum eigenvalue of the unscaled GFEVD matrix. These schemes are denoted, respectively, as "Row Max" and "Spectral" (the later corresponding to spectral radius normalization). 
The "Row Sum" normalization scheme implies that the directional spillovers received from others plus own connectedness add up to one. This results in a straightforward interpretation since the each element of the normalized GFEVD matrix can be interpreted as the share of the variance accounted by each country in the row. This corresponds to the analysis we have performed. Although this property does not hold under the alternative normalization schemes, Caloia et al. (2019) remark the accuracy of the resulting computation of connectedness and the preservation of the sign of the spillovers' net contribution. Hence, to assess the robustness of our results and analysis, Table 9 presents the computation of connectedness for the unemployment rate (Panel A) and the Consumer Price Index (Panel B) using the "Row Sum," "Row Max" and "Spectral" normalization rules.

As expected (see Caloia et al., 2019), the "Row Max" scheme delivers the lowest level of overall connectedness. In turn, the results from the "Spectral" scheme are very close to those from the "Row Sum". Note that, even though the overall spillover indices of UNRATE and LCPI fall by 10.6 and 12.7 percentage points, respectively, under the "Row Max", the signs of net connectedness are retained (with the sole exception of the Italian CPI). In addition, if one ranks connectedness from others resulting from CPI shocks, then the "Row Max" scheme just brings France instead of Germany to the top, followed by the US and Canada; whereas the UK, Italy, and Japan consistently lie at the bottom of the ranking. Moreover, the ordering of UNRATE connectedness from others remains stable, in general, regardless of scaling methods.

Regarding the spectral radius normalization, on the one hand, it tracks the "Row Sum" estimate remarkably well. On the other hand, it agrees with the "Max Row" scheme in terms of the net spillovers' sign and country ranks. The spectral indices of UNRATE and LCPI place overall connectedness just above the "Row Sum" in the first case $(42.23 \%$ versus $41.81 \%)$, and just below in the second (56.90\% versus $58.3 \%$ ). Countrywise, we observe differences in the results of net spillovers of the CPI in France (where they turn out to be quite less positive) and Japan (where they turn out to be dropped by $50 \%$ ).

In the dynamic context, Fig. 7 confirms the remarkable similarity of the results obtained through the "Row Sum" and "Spectral" schemes both for unemployment and the CPI, and confirms the downward bias of connectedness when computed through the "Max Row" scheme. At this point, it is worth recalling Caloia et al. (2019)'s claim that the Max Row normalization should be favored, as it provides a better interpretation than the Spectral counterpart. In any case, neither of these scalar-based normalization schemes provides the ease of interpretation of DY's (2009, 2012) traditional normalization rule, and neither of them delivers evidence against the analysis performed.

\section{Conclusions}

In a world in which economies have become progressively integrated and interdependent, it is crucial to know the extent to which shocks experienced in one country affect other countries. Extant literature has been mainly concerned with financial 


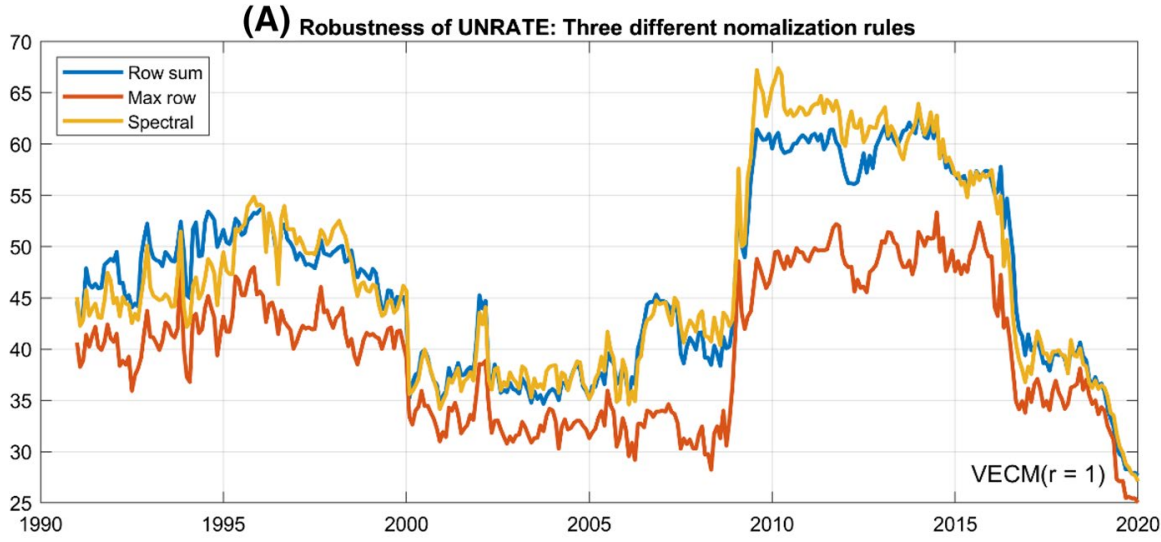

(B) Robustness of LCPI: Three different normalization rules

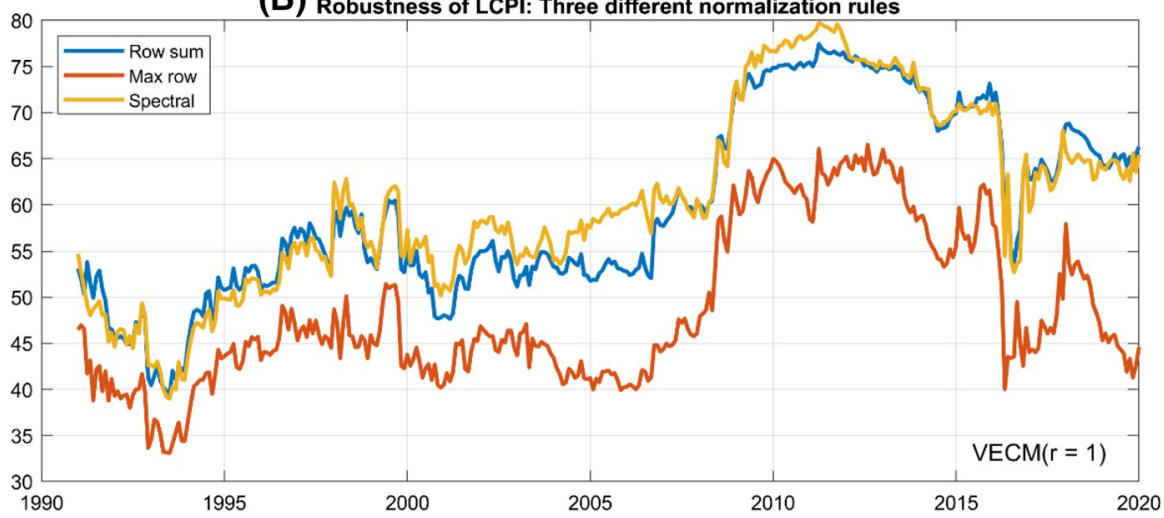

Fig. 7 Sensitivity of time-varying connectedness

shocks, but other shocks take place, and some may have a direct social impact deserving consideration. In this paper, we brought the notion of connectedness to a set of two critical macroeconomic variables such as inflation and unemployment. We explored their level of connectedness among the G7 countries, plus, Spain and found that the asymmetric responses across these variables and economies result in interesting patterns policy wise.

Such patterns have to do with the relative magnitude of directional spillovers to others or from others, which seem to be associated with the situation of the current account balance. This hypothesis is worth to be explored in future research, since no tangible proof of it could be provided in the context of this paper. Such patterns have also to do with the labor market policy and the Phillips Curve trade-off since we showed that there is a twofold incentive for policy makers to increase cross-country coordination. The first incentive is to avoid spillovers from other country-specific shocks, while the second one is to avoid larger sacrifice ratios when having to bring inflation down in a recession. Finally, we uncovered a pattern taking the form of 
increased connectedness in times of economic turmoil such as, for example, the GFC. Such last pattern points to an interlinked behavioral response of economies to country-specific and common shocks. Although the distinction between the two has become common practice in the literature, there seems to be scope for refinement in the context of a growingly interconnected world in which pure local shocks have probably started to become a rarity.

Supplementary Information The online version contains supplementary material available at https://doi. org/10.1007/s00181-021-02052-0.

Acknowledgements We are grateful to two anonymous referees for their insightful comments and suggestions received on an earlier version of this paper. This study was partially funded by the Spanish Ministry of Science and Innovation (grant number PID2019-104723RB-I00). This study was partially funded by the University of Economics Ho Chi Minh City, Vietnam (grant number: None).

Funding This study was partially funded by the Spanish Ministry of Science and Innovation (grant number PID2019-104723RB-I00). This study was partially funded by the University of Economics Ho Chi Minh City, Vietnam (grant number: None).

Code availability Upon reasonable request.

\section{Declarations}

Conflict of interest Binh Thai Pham declares that he has no conflict of interest. Hector Sala declares that he has no conflict of interest.

Ethical approval This article does not contain any studies with human participants or animals performed by any of the authors.

Availability of data and material Upon request.

Consent to participate Not applicable.

Consent for publication Not applicable.

\section{References}

Antonakakis N, Badinger H (2016) Economic growth, volatility, and cross-country spillovers: new evidence for the G7 countries. Econ Modell 52:352-365

Antonakakis N, Breitenlechner M, Scharler J (2015) Business cycle and financial cycle spillovers in the G7 countries. Q Rev Econ Finance 58:154-162

Ball L, Leigh D, Loungani P (2017) Okun's law: Fit at 50? J Money Credit Bank 49(7):1413-1441

Breitung J (2001) The local power of some unit root tests for panel data. In Baltagi BH, Fomby TB, and Hill RC (eds) Nonstationary panels, panel cointegration, and dynamic panels. Emerald Group Publishing Limited (Advances in Econometrics), pp 161-177.

Caloia FG, Cipollini A, Muzzioli, S (2019). How do normalization schemes affect net spillovers? A replication of the Diebold and Yilmaz (2012) study. Energy Econ, 84.

Diebold FX, Yilmaz K (2009) Measuring financial asset return and volatility spillovers, with application to global equity markets. Econ J 119(534):158-171

Diebold FX, Yilmaz K (2012) Better to give than to receive: predictive directional measurement of volatility spillovers. Int J Forecast 28(1):57-66 
Diebold FX, Yilmaz K (2014) On the network topology of variance decompositions: measuring the connectedness of financial firms. J Econ 182(1):119-134

Diebold FX, Yilmaz K (2015) Financial and macroeconomic connectedness: a network approach to measurement and monitoring. Oxford University Press, Oxford

De Grauwe P, Ji Y (2017) The international synchronisation of business cycles: the role of animal spirits. Open Econ Rev 28(3):383-412

Fabiani S, Mestre R (2004) A system approach for measuring the euro area NAIRU. Empirical Econ 29(2):311-341

Im KS, Pesaran MH, Shin Y (2003) Testing for unit roots in heterogeneous panels. J Econ 115(1):53-74

Johansen S (1991) Estimation and hypothesis testing of cointegration vectors in Gaussian vector autoregressive models. Econometrica 59(6):1551-1580

Kapetanios G, Shin Y, Snell A (2003) Testing for a unit root in the nonlinear STAR framework. J Econ 112(2):359-379

Karlsson S, Österholm P (2020) A note on the stability of the Swedish Phillips curve. Empir Econ 59:2573-2612

Kruse R (2011) A new unit root test against ESTAR based on a class of modified statistics. Stat Papers 52(1):71-85

Laubach T (2001) Measuring the NAIRU: evidence from seven economies. Rev Econ Stat 83(2):218-231

Lepetit A (2020) Asymmetric unemployment fluctuations and monetary policy trade-offs. Rev Econ Dyn 36:29-45

Levin A, Lin C-F, Chu C-SJ (2002) Unit root tests in panel data: asymptotic and finite-sample properties. J Econ 108(1):1-24

Miescu MS (2019) Together in bad times? Connectedness and spillovers in recession and boom. Manchester School 87(3):342-366

Monfort M, Ordóñez J, Sala H (2018) Inequality and unemployment patterns in Europe: Does integration lead to (real) convergence? Open Econ Rev 29(4):703-724

Pham BT, Sala H (2019) Government deficit shocks and okun's coefficient volatility: new insights on the austerity versus growth debate. IZA discussion paper, p 12492

Rogoff K (2007) Impact of globalization on monetary policy. The new economic geography: effects and policy implications. In: Federal Reserve Bank of Kansas City, New Economic Geography conference, Kansas City. pp 265-305 